\title{
Intra-operative ocular ultrasonography of iodine-125 brachytherapy plaques in patients with uveal melanoma
}

\author{
Antonio Piñeiro Ces, MD, PhD', Manuel Bande Rodriguez, MD, PhD', Javier Mosquero Sueiro, PhD², \\ Ana María Carballo Castro, MD, PhD³, Ramón Lobato Busto, PhD², Paula Silva Rodriguezl, María Pardo Pérez, PhDl, \\ Francisco Ruiz Oliva-Ruiz, MD, PhDl, Maria Jose Blanco Teijeiro, MD, PhDl \\ 'Unidad de Retina Quirúrgica y Tumores Intraoculares del Adulto, Spain, ${ }^{2}$ Radiophysic Department, Spain, ${ }^{3}$ Radiotherapy Department, Spain
}

\begin{abstract}
Purpose: Brachytherapy with iodine-125 $\left.{ }^{125} \mathrm{I}\right)$ has been extensively used as a conservative treatment for uveal melanoma (UM). Surgical technique for correct placement of episcleral radioactive plaques (ERP) in UM cases with posterior choroidal location and/or small size can be difficult and inaccurate. In this study, the correct positioning of plaques was assessed by intra-operative ultrasound control.

Material and methods: This was a longitudinal, retrospective study of consecutive 20 patients with UM (smallmedium size and/or posterior location) who received ${ }^{125}$ I brachytherapy. Location of plaques was adjusted by intraoperative ocular ultrasonography control. To perform ocular intra-operative ultrasonography, a $10 \mathrm{MHz}$ probe was used to longitudinal and transverse bases in corresponding dummy plaques.

Results: The study included 8 males and 12 females, with a mean age of 66.3 years (SD = 14.53), 5 right eyes (RE) and 15 left eyes (LE). In ultrasound examination, 4 UMs were of mushroom morphology and the rest nodular. Means of the size of UM by ultrasound were $(\mathrm{mm})$ : Lb: $10.60(\mathrm{SD}=2.24) \times \mathrm{Tb}: 9.88(\mathrm{SD}=1.54) \times \mathrm{H}: 4.02(\mathrm{SD}=1.44)(3$ cases corresponding to small size of collaborative ocular melanoma study (COMS), and 17 cases to medium). The plaques used were between 14 and $20 \mathrm{~mm}$ in diameter, with an average distance between the edge of greater base of the tumor and the edge of plate of $2.44 \mathrm{~mm}(\mathrm{SD}=0.34)$. It was necessary to surgically reposition the plaque in 4 cases $(20 \%)$.

Conclusions: Intra-operative ultrasound control improves the accuracy of radioactive plaque placement for the treatment of medium-small UMs in posterior location. Probably, this technique should be applied in all cases of brachytherapy, regardless of the isotope chosen and the location of tumor mass, in order to perfectly adjust therapeutic position.

Key words: ocular ultrasound, uveal melanoma, brachytherapy, iodine-125, tilting.

\section{Purpose}

Uveal melanoma (UM) is the most common primary intraocular malignancy in adults. Fatal liver metastasis occurs in approximately half of the UM cases [1]. Major scientific studies, such as the collaborative ocular melanoma study (COMS), have shown that survival of patients with intermediate-sized UMs treated with enucleation was similar to that after brachytherapy (BT or ERP) with iodine-125 (125I) [1]. Therefore, brachytherapy with ${ }^{125} \mathrm{I}$, ruthenium-106 $\left({ }^{106} \mathrm{Ru}\right)$, and other isotopes has been proposed as a conservative treatment for this disease. Although other forms of radiation therapy for UM (external beam radi- ation therapy - EBRT), including proton beam and gamma knife therapy, are available, they are less affordable than brachytherapy, and all of these treatments have shown very similar local and survival responses [2-6].

Nevertheless, the risk of focal failure (FF) must always be considered for patients undergoing such conservative UM treatments. Therefore, some studies have demonstrated the importance of correct radiotherapeutic techniques to decrease the possibility of FF as much as possible [7-11]. In a recent review of FF rates following conservative brachytherapy for UM, in some analyzed studies, the FF rates ranged from $0 \%$ to $55.8 \%$ [12]. In various cases, surgical technique for the correct placement
Address for correspondence: Antonio Piñeiro Ces, MD, PhD, FEBO, Unidad de Retina Quirúrgica y Tumores Intraoculares del Adulto (URQTIA), Servicio de Oftalmología, Complejo Hospitalario Universitario de Santiago de Compostela, SERGAS, Laboratorio Tumores Intraoculares del Adulto, Fundación IDIS, SERGAS, Universidade de Santiago de Compostela, Rúa Ramín Baltar S/N.,

15705 Santiago de Compostela, Spain, phone: +34 619-302-545, e-mail: antonio.pineiro@usc.es
Received: 29.10 .2020

Accepted: 15.02 .2021

Published: 14.04.2021 
of episcleral radioactive plaques (ERPs) can be difficult and inaccurate, especially when UM is small and/or located in the posterior pole of the eye. On the other hand, UMs can present a poor local response, even with a correct placement of radioactive ERP. These poor responses are normally related to pathological characteristics of $\mathrm{UM}$, necessitating the collection of tumor samples for prognostic biopsy. In cases with a worse survival prognosis, both local response and control of systemic disease should be monitored with equal importance. The ocular oncologist should always keep in mind that every case of FF greatly increases the risk of metastatic death [13-15].

Several studies have demonstrated that correct positioning of ERP [16-24], without inclination or tilt [25], reduce the risk of FF and metastatic death (COMS) [26-29]. As a result, several ocular oncology groups prefer conservative treatments, if ultrasonography control for correct placement of ERP is possible. The present study includes patients from the last five years, who underwent intra-operative ocular ultrasonography for control of ${ }^{125} \mathrm{I}$ ERP positions. Cases involving correction of plaque positions and their respective tilts were studied.

\section{Material and methods}

A longitudinal and retrospective study of consecutive single-cohort cases was conducted. From a total of 78 patients diagnosed with UM and undergoing ${ }^{125}$ I brachytherapy, which was the first and only treatment applied to each patient (from January 2015 to December 2019), the surgical location of ERP was adjusted by intra-operative ocular ultrasonography control in 20 cases. These patients were characterized by smallto-medium sized UMs and/ or posterior choroidal UM location (COMS) [26]. These assessments were performed in clinical sessions and in a consensus with all members. In all cases, the center of UM was posterior to the equator of the globe. Thus, they were classified into posterior pole, posterior periphery, and peripapillary locations.

Collection of patient images was performed in accordance with the tenets of the Declaration of Helsinki. Written informed consent was obtained from all patients, and approval was acquired from the local ethics committee of Galicia (registration code, 2009/128). For each patient, a partial conjunctival peritomy was performed in the operating room under peribulbar anesthesia. The areas for each ERP were initially localized, using standard transillumination and indirect ophthalmoscopy. Rectus muscles were isolated and temporarily sutured to another location if they affected the final placement of ERP.

In each case, dummy ERP (simulation of non-radioactive plaques was prepared using methacrylate with a metal ring on the outer edge) was initially sutured to the episclera. However, the first three cases included in the study were directly analyzed using a conventional ERP, because of the unavailability of dummy plaques at that point. In these cases, intra-operative ocular ultrasonography was performed using sterile lead-protected gloves.

Ocular intra-operative ultrasound was completed in each case with a 10-MHz probe in B-mode of diagnostic ophthalmic ultrasonography system AVISO (Quantel
Medical Inc., France). For examinations, the surgical field was protected by using a sterile plastic cover from the probe to the ultrasonography connection cable (universal case of video camera with risk of infection, Suministros Hospitalarios SA, Spain). On the eye surface, a sterile 2\% carbomer gel was applied in all cases (Viscotears ${ }^{\circledR}$, Bausch and Lomb, Madrid, Spain). Ultrasonographic scans from the longitudinal base $(\mathrm{Lb})$ and transverse base $(\mathrm{Tb})$ were performed in each case, with the purpose of controlling the position of each plaque in relation to the base of UM.

ERP used in this study was between 14 and $20 \mathrm{~mm}$ in diameter, with intervals of $2 \mathrm{~mm}$ (Eckert \& Ziegler BEBIG $\mathrm{GmbH}$, Berlin, Germany), based on the idea of leaving a safety margin of $2 \mathrm{~mm}$ with respect to the largest base of the tumor. This was calculated from ultrasonographic findings for each UM and analyzed by specialists from radiotherapy and radiophysics department in our hospital. For UMs growing around the optic disc, notched plaques were used.

The prescribed radiation dose to the apex of each UM based on the pre-operative ultrasonographic measurement of height was $85 \mathrm{~Gy}$ at a dose-rate of $0.5 \mathrm{~Gy} /$ hour. The dose was calculated using the same approach as that described in the COMS. ERP was prepared in the radiotherapy and radiophysics department. Surgical re-adjustments were made on the basis of the obtained ultrasonographic scans ( $\mathrm{Lb}$ and $\mathrm{Tb}$ ) once the dummy plaque was sutured to the episclera [30]. Therefore, the locations of ERPs were classified by ultrasonography as follows:

- correctly centered: when both ocular ultrasonography scans $\mathrm{Lb}$ and $\mathrm{Tb}$ were correctly located ERP,

- partially off-center: when one of the ocular ultrasonography scans $\mathrm{Lb}$ or $\mathrm{Tb}$ did not locate ERP,

- completely off-center: when both ocular ultrasonography scans $\mathrm{Lb}$ and $\mathrm{Tb}$ did not correctly locate ERP.

Partial or complete ERP-related errors forced their relocations and required a new ocular ultrasonography control. In some of relocations, plaques were slightly moved with respect to the central base of UM, but their positions remained accurate, since they were based on both ultrasonographic scans.

Once the correct location points for each plaque were obtained, an attempt was made to determine the degree of tilt for each plaque, which referred to separations of plaques from the corresponding episclera. In this regard, for peripapillary cases, it was very important to ensure that the notched plaque was perfectly in contact with the optic disc.

Finally, each dummy ERP was removed and replaced with the corresponding ERP, which was sutured using the previously applied thread. Each plaque had six buttonholes, and, in all cases, an attempt was made to suture all buttonholes on each plaque (or at least the most frequent buttonholes located laterally), in order to adjust the final sutures for brachytherapy.

All patients provided informed consent for a prognostic biopsy of UM. Transvitreal biopsies were done using central 27-gauge vitrectomies. In each case, three different tumors samples located on the apex were collected [31]. Sample collection was performed in the same surgical procedure performed before placing the radioac- 
tive ERP. The genomic findings from prognostic biopsy were assessed with SALSA kit, which was used in each patient to obtain results (SALSA MLPA Probemix P027 uveal melanoma; region: chromosomes $1 \mathrm{p}, 3,6,8$; MRC Holland, Amsterdam, The Netherlands).

The results of prognostic biopsy in all patients were considered in metastasis screening. Regardless of the local response in each case, high-risk cases (class 2 findings) were followed up by abdominal nuclear magnetic resonance imaging, every four months for the first three years after brachytherapy. For cases with moderate-risk (class 1 biopsy findings of cases without any result of prognostic biopsy), abdominal ultrasound was performed every six months, for up to five years follow-up $[32,33]$.

\section{Statistical analysis}

Data of patients were tabulated using Microsoft Excel for Mac, version 14.0.0 (Microsoft Corporation, Redmond, WA, USA). A descriptive study was conducted to evaluate different qualitative and quantitative variables. Frequency and percentage analyses of qualitative variables were performed. The mean and standard deviation were determined. Moreover, Fisher's exact test was used for qualitative variables and Mann-Whitney $U$-test for quantitative variables. This analysis was performed with SPSS 21.0 statistical package (SPSS Inc., Chicago, IL, USA). All results were considered statistically significant when $p$-values were $<0.05$.

\section{Results}

Over the last five years, the placement of plaques using intra-operative ultrasound control was performed in $25.64 \%$ of the total number of patients with UM who underwent brachytherapy with ${ }^{125}$ I. A longitudinal and retrospective study of consecutive single-cohort cases was conducted. This study included 20 patients: 8 men and 12 women, all Caucasian; median age, 68.5 years, range, 39-86 years; 5 right eyes (RE) and 15 left eyes (LE). Seven UMs were of amelanotic type (35\%). Five patients have been already under clinical observation because their first diagnosis was choroidal nevus with some risk of transformation. In these cases, the growth of mass and/or the appearance of more risk factors led to the diagnosis of UM, and brachytherapy was proposed and accepted by patients. No complications to the plaque patients with muscular paresis appeared, including those patients who required a new suture.

In the ultrasound study, 4 UMs showed mushroom morphology, while the rest were dome-shaped. The cases with mushroom morphology did not present with irregular shapes. Thus, the apex of melanoma was centered and ultrasonographic crown smaller than the base of the lesion. The median ultrasound UM size was as follows $(\mathrm{mm})$ : Lb: $9.72(\mathrm{IQR}=7.57) \times \mathrm{Tb}: 9.15(\mathrm{IQR}=4.92) \times \mathrm{H}: 3.59$ $(\mathrm{IQR}=5.60)(3$ cases were small-sized COMS, and 17 cases were medium-sized COMS) (Tables 1 and 2) [27]. None of the cases presented with high-risk clinical signs, such as extraocular extension or infiltration of the ciliary body.

Table 1. Clinical characteristics in the patients included in the study (I)

\begin{tabular}{|c|c|c|c|c|c|c|c|c|}
\hline Patient & Age & Sex & Eye & Location & Morphology & $\begin{array}{l}\text { Contact UM } \\
\text { to optic disc }\end{array}$ & $\begin{array}{l}\text { Transformation } \\
\text { from nevi to UM }\end{array}$ & Color UM \\
\hline 1 & 78 & M & LE & 1:30 h-posterior pole & Dome-shaped & No & No & Amelanotic \\
\hline 2 & 74 & W & LE & 5 h-posterior periphery & Dome-shaped & No & No & Brown \\
\hline 3 & 83 & W & LE & 1 h-peripapilar & Dome-shaped & Yes & No & Amelanotic \\
\hline 4 & 80 & $M$ & LE & 6:30 h-peripapilar & Dome-shaped & Yes & No & Brown \\
\hline 5 & 49 & W & RE & 6:30 h-posterior pole & Mushroom & No & No & Brown \\
\hline 6 & 52 & W & LE & $3 \mathrm{~h}$-posterior pole & Dome-shaped & No & No & Brown \\
\hline 7 & 45 & W & LE & $1 \mathrm{~h}$-posterior periphery & Dome-shaped & No & No & Brown \\
\hline 8 & 75 & M & LE & $4 \mathrm{~h}$-posterior pole & Dome-shaped & No & Yes & Amelanotic \\
\hline 9 & 61 & W & LE & 6 h-posterior pole & Dome-shaped & No & Yes & Brown \\
\hline 10 & 55 & W & RE & $8 \mathrm{~h}$-posterior pole & Dome-shaped & No & No & Amelanotic \\
\hline 11 & 55 & M & LE & $1 \mathrm{~h}$-posterior pole & Mushroom & No & No & Brown \\
\hline 12 & 71 & M & LE & 2 h-posterior periphery & Dome-shaped & No & Yes & Amelanotic \\
\hline 13 & 66 & M & RE & 7 h-peripapilar & Dome-shaped & Yes & No & Brown \\
\hline 14 & 79 & W & LE & $4 \mathrm{~h}$-posterior pole & Dome-shaped & No & No & Brown \\
\hline 15 & 72 & M & RE & $3 \mathrm{~h}$-peripapilar & Dome-shaped & Yes & Yes & Brown \\
\hline 16 & 34 & W & RE & $10 \mathrm{~h}$-posterior periphery & Dome-shaped & No & No & Brown \\
\hline 17 & 85 & W & LE & 10 h-posterior periphery & Mushroom & No & No & Brown \\
\hline 18 & 66 & W & LE & $3 \mathrm{~h}$-posterior pole & Dome-shaped & No & No & Amelanotic \\
\hline 19 & 60 & M & LE & $4 \mathrm{~h}$-posterior pole & Mushroom & No & No & Brown \\
\hline 20 & 86 & W & LE & 4 h-posterior pole & Dome-shaped & No & Yes & Brown \\
\hline
\end{tabular}

UM - uveal melanoma 


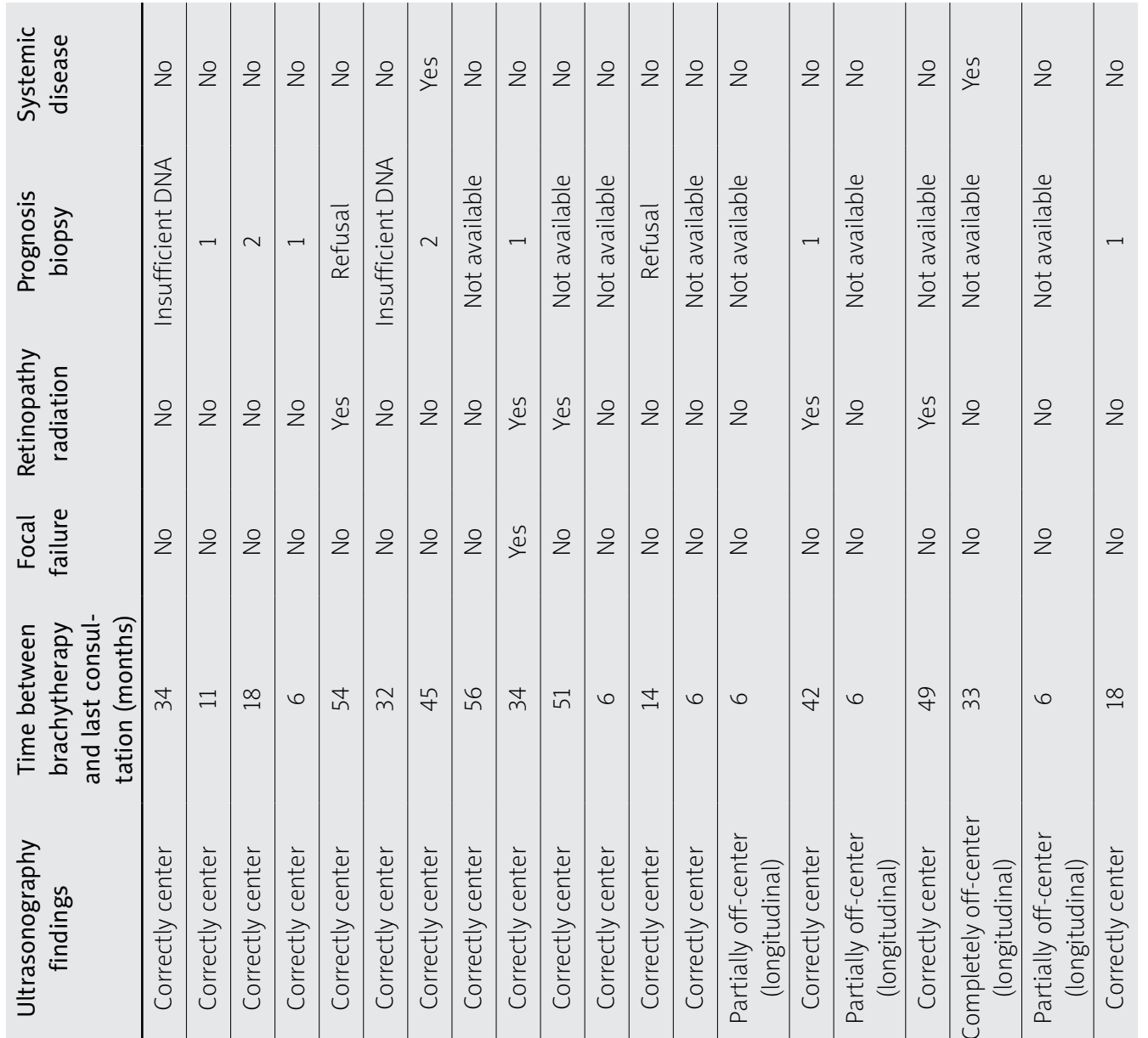

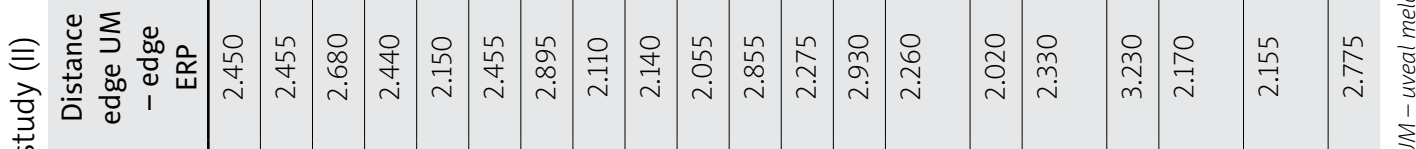

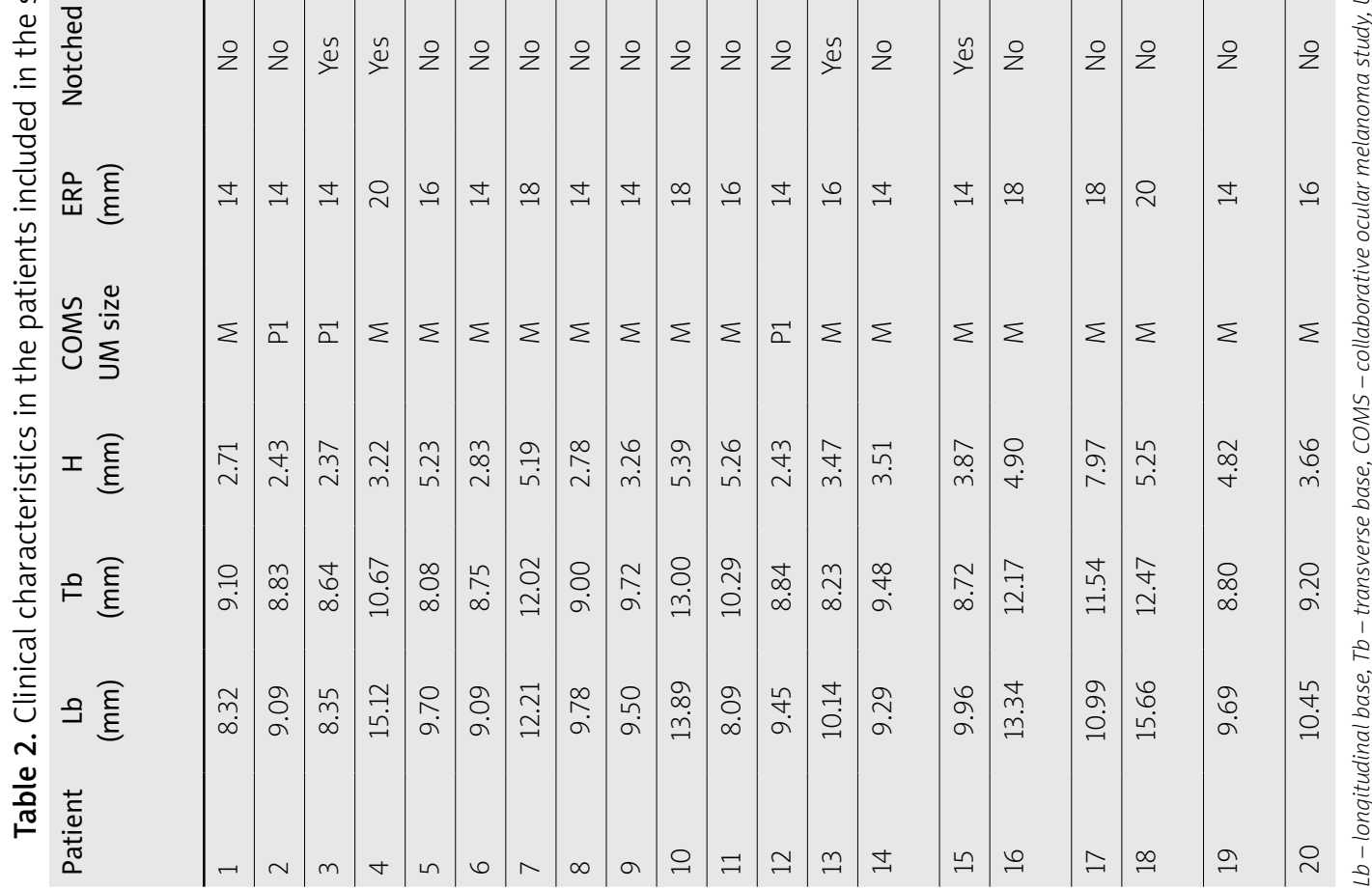


Table 3. Relationships between the correctly center and off-center (longitudinal) center

\begin{tabular}{|c|c|c|c|}
\hline Variable & Correctly center & Off-center (longitudinal) & $P$-value \\
\hline \multicolumn{4}{|l|}{ Sex, $n(\%)$} \\
\hline Men & $7(43.8)$ & $1(25.0)$ & \multirow[t]{2}{*}{0.619} \\
\hline Women & $9(56.3)$ & $3(75.0)$ & \\
\hline \multicolumn{4}{|l|}{ Location, $n(\%)$} \\
\hline Peripapillary & $4(25.0)$ & $0(0.0)$ & \multirow[t]{3}{*}{0.506} \\
\hline Posterior periphery & $4(25.0)$ & $1(25.0)$ & \\
\hline Posterior pole & $8(50.0)$ & $3(75.0)$ & \\
\hline \multicolumn{4}{|l|}{ Morphology, n (\%) } \\
\hline Dome-shaped & $13(81.3)$ & $3(75.0)$ & \multirow[t]{2}{*}{1.000} \\
\hline Mushroom & $3(18.8)$ & $1(25.0)$ & \\
\hline \multicolumn{4}{|c|}{ Contact UM to optic disc, $n(\%)$} \\
\hline No & $12(75.0)$ & $4(100.0)$ & \multirow[t]{2}{*}{0.538} \\
\hline Yes & $4(25.0)$ & $0(0.0)$ & \\
\hline \multicolumn{4}{|c|}{ Transformation from nevi to UM, $n(\%)$} \\
\hline No & $11(68.8)$ & $4(100.0)$ & \multirow[t]{2}{*}{0.530} \\
\hline Yes & $5(31.3)$ & $0(0.0)$ & \\
\hline \multicolumn{4}{|l|}{ COMS, $n(\%)$} \\
\hline$M$ & $13(81.3)$ & $4(100.0)$ & \multirow[t]{2}{*}{1.000} \\
\hline $\mathrm{P} 1$ & $3(18.8)$ & $0(0.0)$ & \\
\hline \multicolumn{4}{|l|}{ Color UM, $n(\%)$} \\
\hline Amelanotic & $5(31.3)$ & $1(25.0)$ & \multirow[t]{2}{*}{1.000} \\
\hline Brown & $11(68.8)$ & $3(75.0)$ & \\
\hline Lb (mm), median (range) & $9.74(8.09-15.12)$ & $11.52(9.29-15.66)$ & 0.345 \\
\hline Tb, median (range) & $9.05(8.08-13.00)$ & $10.83(8.80-12.47)$ & 0.219 \\
\hline $\mathrm{H}(\mathrm{mm})$, median (range) & $3.37(2.37-7.97)$ & $4.86(3.51-5.25)$ & 0.257 \\
\hline
\end{tabular}

Fisher's exact test was used for qualitative variables and Mann-Whitney U test for quantitative variables. Lb - longitudinal base, Tb - transverse base, COMS - collaborative ocular melanoma study, UM - uveal melanoma

Table 4. Comparative results by similar authors

\begin{tabular}{|c|c|c|c|c|c|c|c|}
\hline & Cases & $\begin{array}{l}\text { Re-adjust- } \\
\text { ments }\end{array}$ & $\begin{array}{c}\text { Percentage of cases } \\
\text { re-adjusted }\end{array}$ & $\begin{array}{c}\text { Follow-up } \\
\text { period }\end{array}$ & Tilt presence & Focal failure & $\begin{array}{c}\text { Systemic } \\
\text { disease }\end{array}$ \\
\hline COMS & $\begin{array}{c}1,317 \\
\text { (12 years) }\end{array}$ & Not studied & Not studied & Not studied & Not studied & Not studied & $21 \%$ \\
\hline $\begin{array}{l}\text { Williams et al., } \\
1988\end{array}$ & 16 & Not studied & Not studied & Not studied & Not studied & Not studied & Not studied \\
\hline Pavlin et al., 1989 & 9 & 3 & Not studied & Not studied & Not studied & Not studied & Not studied \\
\hline $\begin{array}{l}\text { Harbour et al., } \\
1996\end{array}$ & 29 & 4 & $14 \%$ & Not studied & Not studied & Not studied & Not studied \\
\hline $\begin{array}{l}\text { Tabandeh et al., } \\
2000\end{array}$ & 117 & 28 & $\begin{array}{c}24 \% \\
1 \text { anterior case } \\
20 \text { posterior cases }\end{array}$ & 37 months & $\begin{array}{c}2 \text { cases } \\
(1.7 \%)\end{array}$ & 2 cases $(1.7 \%)$ & Not detected \\
\hline $\begin{array}{l}\text { Chang et al., } \\
2012\end{array}$ & 150 & 54 & $\begin{array}{c}36 \% \\
15 \text { macula } \\
26 \text { equator } \\
13 \text { periphery }\end{array}$ & $\begin{array}{l}21.5 \text { months } \\
(6-48)\end{array}$ & Not studied & Not studied & Not studied \\
\hline $\begin{array}{l}\text { Badyan et al., } \\
2014\end{array}$ & 526 & 142 & $\begin{array}{c}27 \% \\
\text { (together } \\
\text { re-adjustment } \\
\text { and tilt correction) }\end{array}$ & $\begin{array}{l}53.4 \text { months } \\
(6-175)\end{array}$ & $\begin{array}{c}142 \text { cases } \\
(27 \%)\end{array}$ & 19 (3.6\%) & Not studied \\
\hline $\begin{array}{l}\text { Almony et al., } \\
2008\end{array}$ & 162 & No studied & Not studied & $?$ & $\begin{array}{c}9 \% \text { insertion } \\
53 \% \text { at } \\
\text { plaque } \\
\text { removal } \\
\end{array}$ & $3(2 \%)$ & Not studied \\
\hline Present work & 20 & 4 & $\begin{array}{c}5 \% \\
\text { Posteriors all cases }\end{array}$ & $\begin{array}{c}26.35 \text { months } \\
(6-54)\end{array}$ & $\begin{array}{l}0 \% \text { at inser- } \\
\text { tion }\end{array}$ & $1(5 \%)$ & $2(10 \%)$ \\
\hline
\end{tabular}



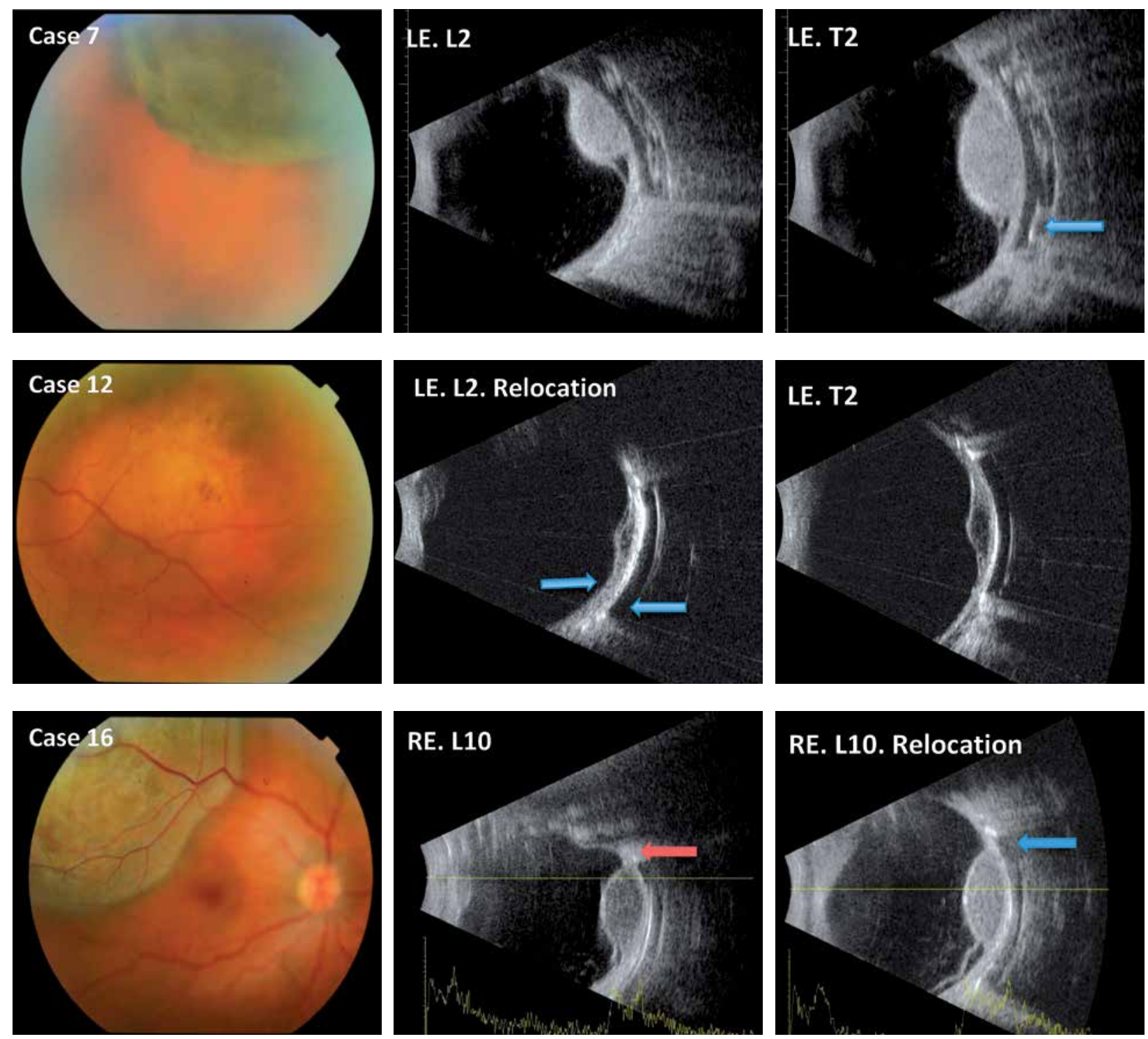

Fig. 1. The main clinical characteristics of three cases are shown. Case 7: Case with correctly centered plaque. The signs of a radioactive plaque placed at the time of the ultrasound study can be detected (blue arrow). Case 12: Case with previously had a partially off-centered in the longitudinal base. This case required relocation in the longitudinal meridian (blue arrows). Finally, the plaque was not perfectly centered but that cover all the base from the UM. Case 16: Case with previously had a complete off-centered in longitudinal and transverse base. The evolution of the error in the longitudinal projection can be seen in these sections, as corrected with the repositioning from red arrow to blue arrow. RE - right eye, LE - left eye, L - longitudinal base and number of equator, $\mathrm{T}$ - transversal base and number equator centered

The distribution of ERPs used was as follows: $14 \mathrm{~mm}$ plaque -10 cases, $16 \mathrm{~mm}$ plaque -4 cases, $18 \mathrm{~mm}$ plaque 4 cases, and $20 \mathrm{~mm}$ plaque - 2 cases. In 4 cases, UM was in contact with the optic nerve, for between $1 / 4$ and $1 / 2$ of the extension. These cases required the use of notched plaques.

The theoretical mean distance between the edge of greater base of the tumor and the plaque's median was 2.385 (IQR = 1.21). The plaque has to be repositioned surgically after being completely off-center in 1 case (5\%) and partially off-centered in 3 cases (15\%). In 16 cases, it was correctly centered (80\%).

Finally, after both $\mathrm{Lb}$ and $\mathrm{Tb}$ ultrasound control, all ERPs were sufficient to cover the tumor base orthogonally. In 4 cases $(20 \%)$, the final position, although completely covering the plaque, was slightly asymmetric with respect to the base of the tumor.

The possible presence of ERP tilting and its detection by ultrasonography was studied. However, no patient showed separation of the plaque from the episclera. The four cases with notched plaques demonstrated a very good correlation between the metallic ring of the dummy and the ultrasonographic shadow of the optic disc.

No significant differences were detected between quantitative and qualitative variables from clinical (Figure 1) and ultrasonographic signs (Table 3).

The results of prognostic biopsy in these patients are presented in Table 2. Class 1 findings were obtained in 
five patients, while class 2 findings were detected in two cases. In one case, the genomic result showed heterogeneity and in two cases, the amount of DNA was insufficient to obtain a result. The rest of the patients could not undergo prognostic biopsy because of their refusal to go through the procedure (2 cases), or due to failure to initiate this technique because of unavailability (8 cases).

The average observation period from the placement of plaques to the time of writing this report was 26.35 months (range, 6-54 months). No other local treatment for UM, such as transpupillary thermotherapy were applied in any of the cases. However, radiation retinopathy with loss of visual acuity was detected in 5 cases. These patients underwent different treatments, including laser panphotocoagulation, periocular corticosteroid injection, anti-VEGF intravitreal injection, and even intraocular injection of intravitreal corticosteroids [34, 35].

All the patients showed an appropriate local response to brachytherapy, except patient number 9 , who showed a choroidal nevus located in the 6 o'clock meridian of LE. Rapid growth of the lesion was observed within the last year, and a treatment with ${ }^{125}$ I brachytherapy was decided in January 2017. Moreover, the patient subsequently underwent additional radiation radiotherapy, and at the end of 2019, another round of brachytherapy with ${ }^{125} \mathrm{I}$ was proposed. The plaque data assessed in the present study were obtained from both plaques. On the other hand, the genomic study revealed class 1 findings. All of the remaining cases demonstrated signs of local response to brachytherapy.

Among the patients who underwent brachytherapy, two showed evidence of subsequent metastasis. These two cases presented with medium-sized UMs with a dome-shaped morphology, one of which was amelanotic, with a good local response. Prognostic biopsies yielded insufficient DNA in one patient and class 2 findings in the other. The intervals between brachytherapy and detection of systemic disease were 32 and 41 months, respectively. Similarly, neither case showed an extraocular extension response. No exact relationship could be determined between cases with metastasis and difficult-to-locate plaques (Table 2).

\section{Discussion}

This study presents a longitudinal and retrospective assessment of patients, in whom UMs were treated with intra-operative ultrasound control to ensure appropriate placement of ${ }^{125} \mathrm{I}$ plaques. The type of UMs included in this study was identified in the last five years, namely, small- or medium-sized UMs that were posteriorly located. The results obtained with ultrasonography control showed that the percentage of error in the location of the plaque was small, comparable to that reported by other authors (Table 4) [16-18, 21, 23-25]. The present study included a much lower percentage of cases, in which ERP had to be re-adjusted. Thus, the correct placement of plaque with ultrasound may be an indication for its use in this type of treatment.

Errors were obtained in this series, especially in the $\mathrm{Lb}$ of ERP placement. We think this result may be related to the posterior position of lesions. This lesion characteristic, especially in cases of amelanotic UMs (35\% of cases), can cause difficulties in transillumination, resulting in discrepancies of many ERPs with the original location of the tumor.

However, in the presented series of patients, the plaques showed no tilt, with marked contact with the episclera throughout their extension. The absence of tilt in these cases was possibly related to the fact that all included patients had posterior UM, which could induce pressure on the eye inside the orbital cavity, when plaques reached their physiological position. These plaques can be sutured to the episclera with up to six gold buttonholes in order to adjust them to the episcleral space. No modifications were noticed in any of the four cases involving procedures around the optic nerve. We believe that this finding was more expected since the edge of the dummy plaque and the shadow of the optic nerve were very well distinguished in the intra-operative ultrasound.

Technically, the exact suturing of such posterior ERPs involves significant technical difficulty and requires a substantial amount of experience in episcleral surgery. We believe that it is important to suture all six ERP buttonholes to ensure that the plaque does not move from its position and tilt signs are avoided as much as possible. Although this requirement increases the surgical time, it also minimizes the risk of FF and systemic disease involvement.

In comparison with other published studies [18], we did not perform other ocular ultrasonographic examinations in our patients during the time of hospitalization and before plaque removal. The authors propose that suturing all six ERP buttonholes to establish each plaque could minimize variabilities. Moreover, we think there are important reasons to avoid additional ultrasound measurements during brachytherapy. Although the examination can be performed over closed eyelids, the resolution of ultrasonography is not sufficient to ensure accurate assessments of both plaque location and tilt. Moreover, these examinations may require a dangerous maneuver, since the probe would have to be placed over the surgical field, leading to the risk of radiation exposure and necessitating the use of lead gloves. Finally, the results obtained in such examinations would not change a previously designed calculation.

The authors have no experience with the location of other ERPs, such as those based on ${ }^{106} \mathrm{Ru}$ [9]. ERPs using this isotope are thinner and require only two suture buttonholes. However, it is unknown whether this technique implies a worsening in the correct placement of plaques.

Assessments of the local response in the UM cases included in the study showed five cases of radioactive retinopathy. These patients were adequately treated according to the usual processes; however, they recovered with very low visual function. Nevertheless, they showed good signs of response to brachytherapy and a progressive decrease in tumor size [29], except in one case. Although this patient (case no. 9) showed class 1 findings in prognostic biopsy, she showed a poor response to brachytherapy. Although the patient did not show a lateral extension of UM, the findings indicated an overall 
growth of the mass and no previous signs of response. None of the results indicated pathological characteristics of this tumor. Therefore, in brachytherapy, the placement of plaque was correct in the first single attempt. In fact, another round of brachytherapy was proposed for this patient. She did not have signs of a systemic disease.

In the remaining 19 patients, the mass response was correct, even in the patients with radioactive retinopathy. Although this study population included a small group of patients with great variation in the average treatment duration, we believe that the high percentage of cases showing a good local response is important.

The results of prognostic biopsy could be obtained in 10 cases. Poor prognosis (class 2) was found in 2 cases, whereas good prognosis (class 1 ) was detected in 5 cases. In the remaining cases, the specimen obtained was insufficient for analysis. Of the two patients who refused this test, one was at high-risk and the other did not show sufficient genomic evidence. In both cases, the UM was medium in size and showed a good response to brachytherapy. These UMs were probably already malignant and therefore presented a worse prognosis in the early stages itself. Although, the statistical data could not be obtained in a few cases, we think that in some cases, even with the correct placement of brachytherapy plaques and good local response, the metastatic disease could occur due to aggressive class of UM at the study entry.

It is important to note that no significant differences were detected in both local and systemic disease cases treated with ultrasonography brachytherapy or without (no results showed). The authors believe that this result was probably related to the small number of cases and the existence of six-month periods in some patients undergoing ERP.

\section{Conclusions}

Brachytherapy with ${ }^{125} \mathrm{I}$ is probably the most common conservative treatment used for posterior UM. Intra-operative ocular ultrasonography control improves the accuracy of radioactive ERP placement for the treatment of small-medium UMs at posterior locations. This technique should probably be applied in all cases of brachytherapy, regardless of the isotope chosen and the location of the tumor mass, in order to perfectly adjust therapeutic position.

\section{Acknowledgements}

Public investigation project "Identificacion de biomarcadores pronóstico para el melanoma uveal", PI16/00143, Instituto de Salud Carlos III, Ministerio de Ciencia e Innovación, Spain.

\section{Disclosure}

The authors report no conflict of interest.

\section{References}

1. Straatsma BR, Fine SL, Earle JD et al. Enucleation versus plaque irradiation for choroidal melanoma. Ophthalmology 1988; 95: 1000-1004.
2. Caminal JM, Quintana M, Pera J et al. Results of iodine-125 radiotherapy in the treatment of uveal melanoma. Arch Soc Esp Oftalmol 2002; 77: 29-38.

3. Kowal J, Markiewicz A, Dębicka-Kumela M et al. Outcomes of I-125 brachytherapy for uveal melanomas depending on irradiation dose applied to the tumor apex - a single institution study. I Contemp Brachytherapy 2018; 10: 532-541.

4. Messineo D, Barile G, Morrone S et al. Meta-analysis on the utility of radiotherapy for the treatment of ocular melanoma. Clin Ter 2020; 170: e89-e98.

5. Char DH, Quivey JM, Castro JR et al. Helium ions versus iodine $125 \mathrm{I}$ in the management of uveal melanoma: a prospective, randomized, dynamically balance trial. Ophthalmology 1993; 100: 1547-1554.

6. Rao YJ, Sein J, Badiyan S et al. Patterns of care and survival outcomes after treatment for uveal melanoma in the postcoms era (2004-2013): a surveillance, epidemiology, and end results analysis. J Contemp Brachytherapy 2017; 9: 453-465.

7. Garretson BR, Robertson DM, Earle JD. Choroidal melanoma treatment with iodine 125 brachytherapy. Arch Ophthalmol 1987; 105: 1394-1397.

8. Karlsson UL, Augsburger JJ, Shields JA et al. Recurrence of posterior uveal melanoma after 60Co epiescleral plaque therapy. Ophthalmology 1989; 96: 382-388.

9. Lommatzsch PK. Beta-irradiation of choroidal melanoma with 106Ru/106Rh applicators: 16 years' experience. Arch Ophthalmol 1983; 101: 713-717.

10. Quivey JM, Augsburger J, Snelling L et al. 125I plaque therapy for uveal melanoma: analysis of the impact of time and dose factors on local control. Cancer 1996; 77: 2356-236.

11. Kowal J, Markiewicz A, Dębika-Kumela M et al. Analysis of local recurrence causes in uveal melanoma patients treated with ${ }^{125}$ I brachytherapy - a single institution study. J Contemp Brachytherapy 2019; 11: 554-562.

12. Tagliaferri L, Pagliara MM, Fionda B et al. Personalized re-treatment strategy for uveal melanoma local recurrences after interventional radiotherapy (brachytherapy): single institution experience and systematic literature review. J Contemp Brachytherapy 2019; 11: 54-60.

13. Vrabec TR, Augsburger JJ, Gamel JW et al. Impact of local tumor relapses on patient survival after cobalt 60 plaque radiotherapy. Ophthalmology 1991; 98: 984-988.

14. Gragoudas ES, Egan KM, Seddon JM et al. Intraocular recurrence of uveal melanoma after proton beam irradiation. Ophthalmology 1992; 99: 760-766.

15. De Potter P, Shields CL, Shields JA et al. Plaque radiotherapy for juxtapapillary choroidal melanoma: visual acuity and survival outcome. Arch Ophthalmol 1996; 114: 1357-1365.

16. Williams DF, Mieler WF, Lewandowski M et al. Echographic verification of radioactive plaque position in the treatment of melanomas. Arch Ophthalmol 1988; 106: 1623-1624.

17. Pavlin CJ, Japp B, Simpsom ER et al. Ultrasound determination of the relationship of radioactive plaqued to the base of choroidal melanomas. Ophthalmology 1989; 96: 538-542.

18. Harbour JW, Murray TG, Byrne SF et al. Intraoperative echographic localization of iodine 125 episcleral radioactive plaques for posterior uveal melanoma. Retina 1996; 16: 129-134.

19. Anteby II, Pe'er J. Need for confirmation of positioning of ruthenium plaques by postoperative B-scan ultrasonography. Ophthalmic Surg Lasers 1996; 27: 1024-1029.

20. Finger PT, Romero JM, Rosen RB et al. Three-dimensional ultrasonography of choroidal melanoma: localization of radioactive eye plaques. Arch Ophthalmol 1998; 116: 305-312

21. Tabandeh H, Chaudhry NA, Murray TG et al. Intraoperative echographic localization of iodine-125 episcleral plaque for brachytherapy of choroidal melanoma. Am J Ophthalmol 2000; 129: 199-204. 
22. Al Mahmoud T, Mansour M, Deschenes J et al. Intraoperative echographic localization for radioactive ophthalmic plaques in choroidal melanoma. Ann N Y Acad Sci 2008; 1138: 10-14.

23. Chang MY, Kamrava M, Demanes DJ et al. Intraoperative ultrasonography-guided positioning of iodine 125 plaque brachytherapy in the treatment of choroidal melanoma. Ophthalmology 2012; 119: 1073-1077.

24. Badiyan SN, Rao RC, Apicelli AJ et al. Outcomes of iodine-125 plaque brachytherapy for uveal melanoma with intraoperative ultrasonography and supplemental transpupillary thermotherapy. Int J Radiation Oncol Biol Phys 2014; 88: 801-805.

25. Almony A, Breit S, Zhao $\mathrm{H}$ et al. Tilting of radioactive plaques after initial accurate placement for treatment of uveal melanoma. Arch Ophthalmol 2008; 126: 65-70.

26. Diener-West M, Earle JD, Fine SL et al. Collaborative Ocular Melanoma Study Group. The COMS randomized trial of iodine 125 brachytherapy for choroidal melanoma, III: initial mortality findings. COMS Report No. 18. Arch Ophthalmol 2001; 119: 969-982.

27. Collaborative Ocular Melanoma Study (COMS) Group. The COMS randomized trial of iodine-125 brachytherapy for choroidal melanoma $\mathrm{V}$ : twelve-year mortality rates and prognostic factors. COMS Report No. 28. Arch Ophthalmol 2006; 124: 1684-1693.

28. Collaborative Ocular Melanoma Study. Design and methods of a clinical trial for a rare condition: the Collaborative Ocular Melanoma Study. COMS Report No. 3. Control Clin Trials 1993; 14: 362-391.

29. Ophthalmic Oncology Task Force. Local recurrence significantly increases the risk of metastatic uveal melanoma. Ophthalmology 2016; 123: 86-91.

30. Byrne SF, Green RL. Ultrasound of the eye and orbit. Mosby, Philadelphia 2002.

31. Singh AD, Aziz HA, Pelayes D et al. Twenty-five-gauge cannula-assisted fine-needle aspiration biopsy of choroidal melanoma: cytopathological analysis. Retina 2017; 37: 1674-1677.

32. Onken MD, Worley LA, Char DH et al. Collaborative Ocular Oncology Group report number 1: prospective validation of a multi-gene prognostic assay in uveal melanoma. Ophthalmology 2012; 119: 1596-1603.

33. Bellerive C, Ouellet E, Kamaya A et al. Liver imaging techniques: recognition of uveal melanoma metastases. Ocul Oncol Pathol 2018; 4:254-260

34. Ramaya KJ, Harbour JW. Current management of uveal melanoma. Expert Rev Ophthalmol 2007; 2: 939-946.

35. Jensen AW, Petersen IA, Kline RW et al. Radiation complications and tumour control after 125I plaque brachytherapy for ocular melanoma. Int J Radiat Oncol Biol Phys 2005; 63: 101-108. 